\title{
A Two-stage Process for Increasing the Yield of Prebiotic-rich Extract from Pinus densiflora ${ }^{1}$
}

\author{
Ji Young Jung ${ }^{2} \cdot$ Jae-Kyung Yang $\mathbb{D}^{2, \dagger}$
}

\begin{abstract}
The importance of polysaccharides is increasing globally due to their role as a significant source of dietary prebiotics in the human diet. In the present study, in order to maximize the yield of crude polysaccharides from Pinus densiflora, response surface methodology (RSM) was used to optimize a two-stage extraction process consisting of steam explosion and water extraction. Three independent main variables, namely, the severity factor $(R o)$ for the steam explosion process, the water extraction temperature $\left({ }^{\circ} \mathrm{C}\right)$, and the ratio of water to raw material $(\mathrm{v} / \mathrm{w})$, were studied with respect to prebiotic sugar content. A Box-Behnken design was created on the basis of the results of these single-factor tests. The experimental data were fitted to a second-order polynomial equation for multiple regression analysis and examined using the appropriate statistical methods. The data showed that both the severity factor $(R 0)$ and the ratio of water to material $(\mathrm{v} / \mathrm{w})$ had significant effects on the prebiotic sugar content. The optimal conditions for the two-stage process were as follows: a severity factor $(R o)$ of 3.86 , a water extraction temperature of $89.66^{\circ} \mathrm{C}$, and a ratio of water to material $(\mathrm{v} / \mathrm{w})$ of 39.20. Under these conditions, the prebiotic sugar content in the extract was $332.45 \mathrm{mg} / \mathrm{g}$.
\end{abstract}

Keywords: Pinus densiflora, prebiotic sugar, steam explosion, water extraction, response surface methodology

\section{INTRODUCTION}

Prebiotic sugars such as polysaccharides, oligosaccharides, and non-digestible carbohydrates have garnered great interest as functional food ingredients because they can alter the composition of the colonic microbiota in the human gut (Rycroft, Jones, Gibson and Rastall, 2001). These sugars have diverse structures and compositions that affect their functional properties and have long been used to improve the texture, water retention, and stabilization of emulsions.
Furthermore, they are increasingly incorporated into health foods due to their prebiotic effect and their role as dietary fibers and mimetic fats (Warrand, 2006). Till date, prebiotic sugars that satisfy this definition include fructo-oligosaccharides, inulin, galacto-oligosaccharides, and gluco-oligosaccharides (Macfarlane et al., 2006). Several non-digestible food ingredients that are emerging as prebiotic sugar candidates include lactulose, galactans, fructans, xylo-oligosaccharides, $\beta$-glucans, or arabinoxylans (Sabater-Molina et al., 2009).

Recently, prebiotic sugars from various foods such

\footnotetext{
${ }^{1}$ Date Received March 2, 2018, Date Accepted July 6, 2018

2 Division of Environmental Forest Science and Institute of Agriculture \& Life Science, Gyeongsang National University, Jinju 52828, Republic of Korea

† Corresponding author: Jae-Kyung Yang (e-mail: jkyang@gnu.ac.kr, ORCID: 0000-0003-0423-6398)
} 
as pomegranate peel (Zhu et al., 2015), Spirulina platensis (Kurd and Samavati, 2015), Clematis huchouensis Tamura (Zhang et al., 2014), longan pulp (Zhong and Wang, 2010), cereal (Michida et al., 2006), mushrooms (Aida et al., 2009), herbs (Guo et al., 2004), chicory root (Roberfroid, 2000), citrus fruits (Sendra et al., 2008), soybean (Crittendan and Playne, 1996), and potatoes (MacFarlane et al., 2006) have gained attention as alternative food supplements.

Moreover, lignocellulosic biomass seems to be a potential source for prebiotic sugars, since it contains carbohydrates such as cellulose (glucan) and hemicelluloses (arabinan, xylan, mannan, and galactan) (Linares-Pasten et al., 2014).

Meanwhile, steam explosion is a simple, low-cost, and environmentally friendly technology that causes hemicellulose depolymerization into soluble oligomers and lignin transformation, taking advantage of its high temperature profile (Lee et al., 2010). During steam explosion, a part of the lignocellulosic biomass becomes solubilized as polymers or monomers, while the other part becomes degraded or transformed into new components.

Recently, numerous reports have described the use of the response surface methodology (RSM) for the optimization of the extraction of polysaccharides from lignocellulosic biomasses, followed by the determination of the antioxidant properties of the extracted polysaccharides (Jung et al., 2012; Kim et al., 2015). RSM is a collection of statistical and mathematical techniques useful for the development, improvement, and optimization of processes. The main advantage of RSM is that it reduces the number of experimental trials needed to evaluate multiple variables and their interactions. However, to the best of our knowledge, there is no report on the use of RSM for the optimization of the conditions required for the extraction of a prebiotic-rich extract from $P$. densiflora or on the determination of their prebiotic activities. Although several studies have explored the steam explosion and extraction stages separately, optimizing the operating variables for each independent process, none of the studies have reported the simultaneous optimization of the two stages. Therefore, the aim of this study was to use RSM for the determination of the optimal operating factors in a two-stage process designed to obtain the highest yield of prebiotic sugars from $P$. densiflora extracts. We also investigated the prebiotic activity of the extracts.

\section{MATERIALS and METHODS}

\subsection{Raw material}

Pinus densiflora was collected from the forest around the city of Hongcheon in South Korea. P. densiflora were chipped to a particle size of approximately $2 \times$ $2 \times 0.5 \mathrm{~cm}^{3}$ for steam explosion and stored at $20{ }^{\circ} \mathrm{C}$ at a moisture level below $10 \%-15 \%$.

\subsection{Steam explosion}

The chipped raw material was treated according to the conditions derived from the statistical model (Table 1). Each experimental condition was represented by a severity factor, which unifies time ( $t$, min) and temperature $\left(\mathrm{T},{ }^{\circ} \mathrm{C}\right)$ in a single factor and allows to compare the different treatment conditions. The severity factor was calculated using equation (1) (Fernandez et al., 1999, Jung and Yang, 2016).

Severity factor $(R 0)=\mathrm{t} * \exp (\mathrm{T}-100 / 14.75) \cdots \cdots(1)$

Steam temperatures of $160{ }^{\circ} \mathrm{C}$ to $220{ }^{\circ} \mathrm{C}$ and treatment times of 5 to $15 \mathrm{~min}$ were used to achieve the following values for the severity factor $(R o): 2.47$, 3.05, 3.36, 3.53, 3.64, 3.94, 4.12, 4.23, 4.53, and 4.71 (Table 1). 
Table 1. Steam explosion conditions

\begin{tabular}{ccc}
\hline Temperature $\left({ }^{\circ} \mathrm{C}\right)$ & Time (min) & $\begin{array}{c}\text { Severity factor } \\
(\text { Ro })^{\mathrm{a}}\end{array}$ \\
\hline \hline 160 & 5 & 2.47 \\
180 & 5 & 3.05 \\
& 10 & 3.36 \\
& 15 & 3.53 \\
& 5 & 3.64 \\
& 10 & 3.94 \\
& 15 & 4.12 \\
& 5 & 4.23 \\
& 10 & 4.53 \\
& 15 & 4.71 \\
\hline
\end{tabular}

${ }^{\mathrm{a}}$ Severity factor $(\mathrm{Ro})=\mathrm{t} * \exp (\mathrm{T}-100 / 14.75)$

\subsection{Single-factor experiments}

Each steam-exploded wood sample (severity factor $(R o)=2.47-4.71,1 \mathrm{~g})$ was treated in a $250-\mathrm{mL}$ flat-bottomed beaker with the determined extraction ratio of water to raw material $(10-50, \mathrm{~mL} / \mathrm{g})$ at an extraction temperature of $60{ }^{\circ} \mathrm{C}$ to $100{ }^{\circ} \mathrm{C}$ for an extraction time of 30 to $300 \mathrm{~min}$. After the water extraction step, the resulting extracts were collected by centrifugation at 4,000 rpm for $15 \mathrm{~min}$.

\subsection{Experimental design of the response surface methodology}

A three-variable Box-Behnken design (BBD) was used to optimize the two-stage process for the extraction of prebiotic sugars from $P$. densiflora. The selected variables were, namely, the severity factor $(R o)$ of steam explosion and temperature $\left({ }^{\circ} \mathrm{C}\right)$ and the ratio of water to material $(\mathrm{mL} / \mathrm{g})$ for water extraction, the ranges for which were defined as 3.64-4.12 for the severity factor, $80{ }^{\circ} \mathrm{C}-100{ }^{\circ} \mathrm{C}$ for the temperature, and 30-50 for the ratio of water to material $(\mathrm{mL} / \mathrm{g})$. The levels of the variables were determined from a single-factor experimental analysis. The three variables were $X_{1}$
Table 2. Experiments performed and coded values of the variables using the Box-Behnken design

\begin{tabular}{cccc}
\hline & \multicolumn{3}{c}{ Independent variables } \\
\cline { 2 - 4 } Run & $\begin{array}{c}X_{1}, \\
\text { Severity } \\
\text { factor (Ro) }\end{array}$ & $\begin{array}{c}X_{2}, \\
\text { Extraction } \\
\text { temperature } \\
\left({ }^{\circ} \mathrm{C}\right)\end{array}$ & $\begin{array}{c}X_{3}, \\
\text { Ratio of } \\
\text { water to } \\
\text { material } \\
\text { (mL/g) }\end{array}$ \\
\hline \hline 1 & 1 & 0 & -1 \\
2 & 0 & 0 & 0 \\
3 & 1 & 0 & 1 \\
4 & -1 & 1 & 0 \\
5 & 0 & 0 & 0 \\
6 & 0 & -1 & -1 \\
7 & -1 & 0 & -1 \\
8 & 1 & -1 & 0 \\
9 & -1 & 0 & 1 \\
10 & 0 & -1 & 1 \\
11 & 1 & 1 & 0 \\
12 & 0 & 1 & 1 \\
13 & 0 & 0 & 0 \\
14 & 0 & 0 & 0 \\
15 & -1 & -1 & 0 \\
16 & 0 & 1 & -1 \\
17 & 0 & 0 & 0 \\
\hline
\end{tabular}

(severity factor), $X_{2}$ (extraction temperature), and $X_{3}$ (ratio of water to material), and the three levels were coded 1,0 , and -1 for high, intermediate, and low levels, respectively. Table 2 lists the $\mathrm{BBD}$ matrix of the experiment with 17 trials and the response values used to develop the model. The experiments were performed in a random order to minimize the effects of external factors without taking the experimental design into account.

On the basis of the experimental data, a second-order polynomial model was established, which correlated the association between prebiotic sugar content and steam explosion treatment (severity factor, $R o$ ) and the variables of the water extraction method (extraction temperature in ${ }^{\circ} \mathrm{C}$, and ratio of water to material $\left.(\mathrm{mL} / \mathrm{g})\right)$. 
The second-order polynomial model was given by equation (2):

$$
Y=\beta_{0}+\sum_{i=1}^{3} \beta_{i} X_{i}+\sum_{i=1}^{3} \beta_{i i} X_{i}^{2}+\sum_{\substack{i=1 \\ i<j}}^{2} \sum_{i=2}^{3} \beta_{i j} X_{i} X_{j}
$$

where $X_{1}, X_{2}$, and $X_{3}$ are the independent variables affecting the responses of $Y$, and $\beta_{0}, \beta_{i}(i=1,2$, and 3), $\beta_{i i}(i=1,2$, and 3$)$, and $\beta_{i j}(i=1,2$, and 3$)$ are the regression coefficients for the intercept, linear, quadratic, and cross-product terms, respectively (Jung et al., 2017).

\subsection{Analytical methods}

\subsubsection{Carbohydrate composition}

The carbohydrate compositions of the raw material and steam-exploded wood (solid and liquid fractions) were determined according to the procedures of the American Society for Testing and Materials (ASTM). Thus, the carbohydrate composition was determined on the basis of the monomer content, which was measured after a two-step acid hydrolysis procedure for the fractionation of the fibers. The first step involved adding $72 \% \mathrm{H}_{2} \mathrm{SO}_{4}$ at $30{ }^{\circ} \mathrm{C}$ for $60 \mathrm{~min}$. In the second step, the reaction mixture was diluted with $4 \% \mathrm{H}_{2} \mathrm{SO}_{4}$ and autoclaved at $121{ }^{\circ} \mathrm{C}$ for $1 \mathrm{~h}$. The sugar content of this hydrolysate was then analyzed by gas chromatography (GC) following sulfuric acid hydrolysis and conversion to alditol acetates. The analysis was performed using a gas chromatograph system (YL6100 GC, Young Lin Ins. Co., Ltd. Korea) equipped with a DB-225 capillary column $15 \mathrm{~m}$ long with an inner diameter of $0.25 \mathrm{~mm}$ and a film thickness of $0.25 \mathrm{~mm}$ (Agilent Technologies, USA). Each sample (2 uL) was injected via a split injector $\left(200{ }^{\circ} \mathrm{C}\right.$, split ratio of 30:1) into the DB-225 capillary column. The column temperature program was set as follows: The initial column temperature was $190{ }^{\circ} \mathrm{C}$ (held for $1 \mathrm{~min}$ ), and then it was increased to $220{ }^{\circ} \mathrm{C}$ at $10{ }^{\circ} \mathrm{C} / \mathrm{min}$ (held for $10 \mathrm{~min}$ ) with a total run time of $17 \mathrm{~min}$. The carrier gas was nitrogen (flow rate of $40 \mathrm{~cm} / \mathrm{s}$ ) and the detector was set at $70 \mathrm{eV}$. The standard curve for each monosaccharide, using myo-inositol as the internal standard, was determined by plotting the concentration ratio against its area ratio.

\subsubsection{Prebiotic sugar content}

The prebiotic sugar content was estimated using the phenol-sulfuric acid colorimetric method (Dubois et al., 1956). The samples $(0.6 \mathrm{~mL})$ and the phenol solution $(0.3 \mathrm{~mL})$ were placed in screw-capped tubes $(13 \times 100 \mathrm{~mm})$, which were then capped and vortex-stirred. Following this, $1.5 \mathrm{~mL}$ of concentrated $\mathrm{H}_{2} \mathrm{SO}_{4}$ was added either directly against the liquid surface over 2 or $10 \mathrm{~s}$ or slowly down the side of each tube. The tubes were then closed, vortex-stirred for $5 \mathrm{~s}$, and incubated for $15 \mathrm{~min}$ at $100{ }^{\circ} \mathrm{C}$. All the tubes were allowed to cool to room temperature before the absorbance was measured at $490 \mathrm{~nm}$, using distilled water as the blank, in a UVvisible spectrophotometer (HITACHI U-3000, Tokyo, Japan); the final quantification was based on a glucose calibration curve.

\subsubsection{Prebiotic activity}

The probiotic strains used in this study included Bifidobacterium animalis subsp. animalis, Bifidobacterium breve, Bifidobacterium longum, Bifidobacterium bifidum, Lactobacillus casei, Lactobacillus acidophilus, Lactobacillus delbrueckii subsp. bulgaricus, Enterococcus faecium, Enterococcus faecalis, Bacillus subtilis, Bacillus coagulans, Lactococcus gasseri, and Streptococcus salivarius subsp. thermophilus. The probiotic activity of the strains in the presence of the prebiotic sugars extracted from $P$. densiflora, at the optimal two-stage process conditions, was determined by measuring the optical density using a UV-visible spectrophotometer (HITACHI U-3000, Tokyo, Japan). In this method, the change in OD at $600 \mathrm{~nm}$ was measured, which 
indicated turbidity and, thus, growth of the probiotic microorganisms. The number of cells required for an initial OD value of 0.1 at $600 \mathrm{~nm}$ were harvested and inoculated in de Man, Rogosa, and Sharpe (MRS) medium without sugar. The positive control was incubated in MRS medium, and the samples were incubated at $37{ }^{\circ} \mathrm{C}$ for $48 \mathrm{~h}$; the OD was measured at $600 \mathrm{~nm}$ after mixing for 15 seconds.

\subsection{Statistical analysis}

Regression analysis and ANOVA were performed using Design-Expert, version 10 to assess the combined effect of the variables on the responses according to the full quadratic polynomial model with a confidence level of $95 \%(p=0.05)$. All the experiments were performed in triplicate, and the mean values were reported as responses in the RSM model.

\section{RESULTS and DISCUSSION}

\subsection{Effect of steam explosion conditions on the carbohydrate composition of $P$. densiflora}

The carbohydrate composition of the solid fraction

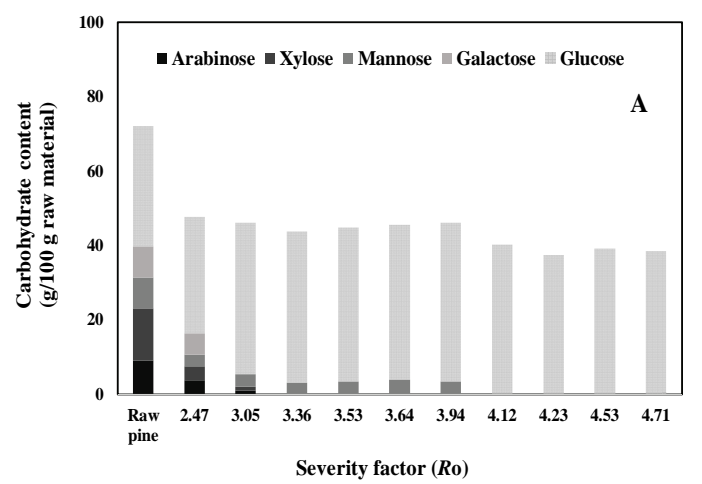

obtained after each steam explosion treatment is shown in Fig. 1, which also shows the expected decrease in the carbohydrate content of the steam-exploded $P$. densiflora solid fraction as the severity factor increased. This result was mainly observed due to the removal of hemicelluloses, as some authors have shown previously (Martin-Sampedro et al., 2014). The proportion of the sugars that were not detected in the solid fraction after treatment at a severity factor of 4.12-4.71 depended on the type of the hemicellulosic sugar (i,e., arabinose, xylose, mannose, or galactose). Generally, hemicellulose undergoes considerable decomposition at temperatures ranging from $200{ }^{\circ} \mathrm{C}$ to $300{ }^{\circ} \mathrm{C}$, and some small phenolic fragments are released from lignin within the temperature range of steam explosion (Tumuluru et al., 2011). The carbohydrate composition of the liquid fraction obtained after water extraction of the steamexploded $P$. densiflora is shown in Fig. 1. The carbohydrate content initially increased with the severity factor $(R o)$ for steam explosion, and then slowly decreased. This trend can be ascribed to a balance between depolymerization of the oligomeric sugars and secondary degradation of the monomeric products. The increase in the content of arabinose, xylose, and galactose after steam explosion, albeit still significant, was lower than that for mannose and glucose. Arabinose,

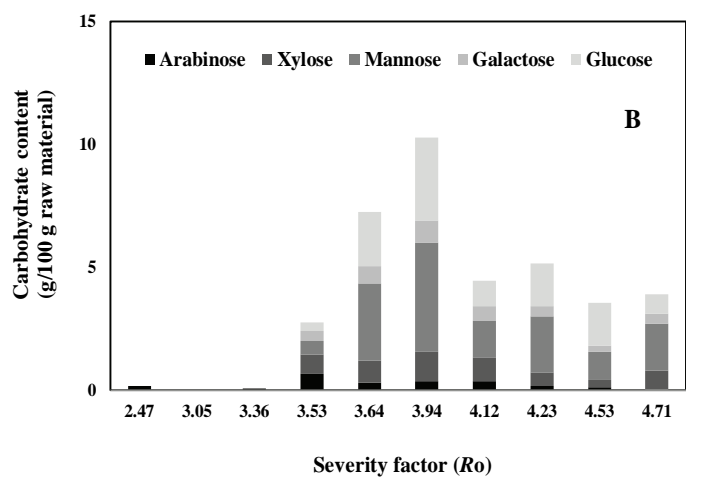

Fig. 1. Carbohydrate content of the solid (A) and liquid (B) fractions obtained from different steam explosion conditions. 
which is the least stable of the oligomeric sugars, was completely depolymerized during steam explosion, and in some cases, the yield of arabinose actually decreased because of secondary degradation.

Cellulose and hemicellulose are among the polysaccharides that can undergo considerable changes at a critical temperature of $120^{\circ} \mathrm{C}$. Hemicellulose is more sensitive to temperature and is easier to degrade than cellulose. During steam explosion, cellulose and hemicellulose were degraded, and polysaccharides with low molecular weights were generated from the hemicellulose (Zhang et al., 2006).

\subsection{Single-factor experimental analysis}

To investigate the influence of different steam
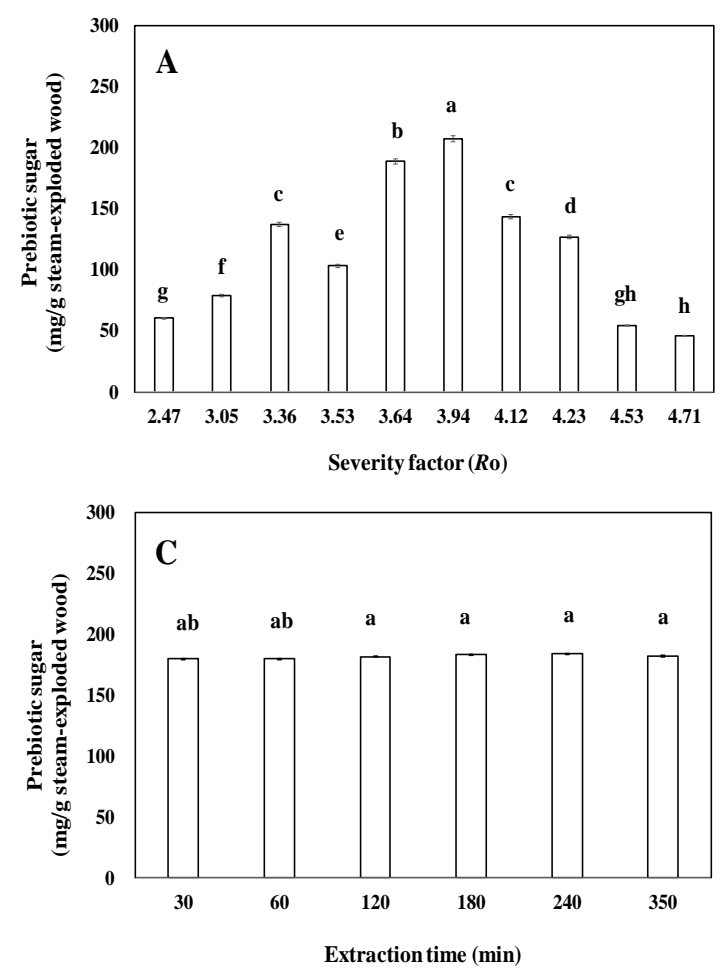

explosion conditions on the prebiotic sugar content of P. densiflora, steam explosion was performed using the following different severity factor $(R 0)$ values: 2.47 , 3.05, 3.36, 3.53, 3.64, 3.94, 4.12, 4.23, 4.53, and 4.71 (Fig. 2A). The extraction temperature, extraction time, and the ratio of water to the material were fixed at $60{ }^{\circ} \mathrm{C}, 60 \mathrm{~min}$, and 30, respectively. As shown in Fig. $2 \mathrm{~A}$, the maximum prebiotic sugar content was observed when the severity factor $(R o)$ was 3.94. Therefore, severity factor $(R o)$ values in the range of 3.64 to 4.12 were evaluated in the present study.

The extraction temperature is one of the most important variables affecting the extraction of prebiotic sugars; an optimum extraction temperature is required to assure the maximum prebiotic sugar extraction by water extraction. Other factors were set as follows: the
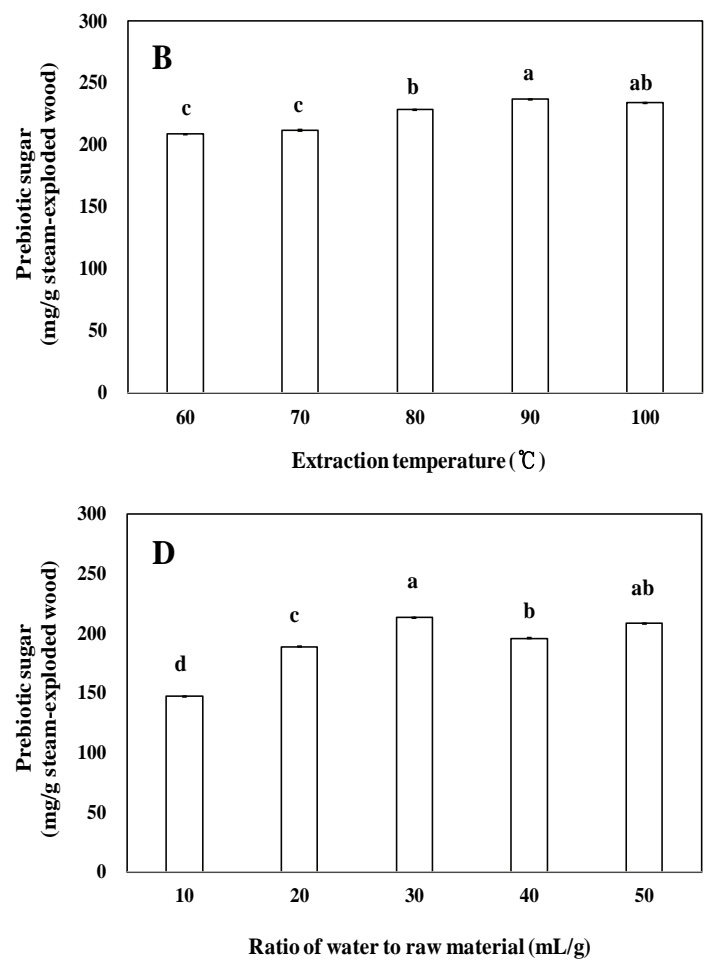

Fig. 2. Effect of different (A) severity factor values, (B) extraction temperature, (C) extraction time, and (D) ratio of water to material on the prebiotic sugar content of $P$. densiflora. 
severity factor $(R o)$ at 3.94 , the extraction time at 60 min, and the ratio of water to material at 30. From the data, we observed that the prebiotic sugar content increased and reached a maximum at $90{ }^{\circ} \mathrm{C}$, after which it declined slightly (Fig. 2B). Therefore, extraction temperatures ranging from $80{ }^{\circ} \mathrm{C}$ to $100{ }^{\circ} \mathrm{C}$ were investigated in the present work.

The different extraction times were set at 30, 60, $120,180,240$, and $300 \mathrm{~min}$ to evaluate the effect of the extraction time on the prebiotic sugar content, setting the other extraction conditions as follows: a severity factor of 3.94, an extraction temperature of $90{ }^{\circ} \mathrm{C}$, and a ratio of water to material of 30 (Fig. 2C). Fig. 2C shows that the prebiotic sugar content was not correlated with an increase in extraction time, with the prebiotic sugar content being $181.7 \mathrm{mg} / \mathrm{g}$ at an extraction time of $120 \mathrm{~min}$. Although the prebiotic sugar content was high when the extraction time was $180 \mathrm{~min}$, increasing the extraction time would increase the cost of the extraction process from an industrial point of view. For this reason, an extraction time of 120 min was used in the present study.

The effect of changing the ratio of water to material (10, 20, 30, 40, and 50) on the prebiotic sugar content was also investigated, while maintaining the other three factors as follows: the severity factor $(R o)$ at 3.94 , the water extraction temperature at $90{ }^{\circ} \mathrm{C}$, and the extraction time at $120 \mathrm{~min}$. Fig. 2D shows that the ratio of water to material had a significant effect on the prebiotic sugar content. When the ratio was increased from 10 to 30 , the prebiotic sugar content increased significantly. However, the data also suggests that a higher ratio of water to material (40 and 50) may lead to a decrease in the prebiotic sugar content. Thus, a water to material ratio of 30-50 was used for further investigation. In summary, we set the following range of parameters for the response surface methodology experiments on the basis of these single-parameter studies: a steam explosion severity factor (Ro) of 3.94-4.12, a water extraction temperature ranging from $80{ }^{\circ} \mathrm{C}$ to $100{ }^{\circ} \mathrm{C}$, and a ratio of water to material of $30-50(\mathrm{~mL} / \mathrm{g})$.

\subsection{Optimization of the two-stage process for prebiotic sugar extraction from $P$. densiflora}

A box-Behnken design (BBD) is more efficient for conducting experiments compared with traditional methods, since it simplifies the complexity of the experimental trials needed to evaluate multiple variables and their interactions.

The main goal of the steam explosion step is to modify the structure of the lignocellulosic biomass to increase the yield of the main component. The effectiveness of the steam explosion method was evaluated by performing prebiotic sugar tests on the liquid fraction extracted from $P$. densiflora using RSM to optimize the three independent variables: severity factor, water extraction temperature, and ratio of water to material. The objective of the experimental design was to optimize the steam explosion (severity factor $(R o)$ ) and water extraction conditions (extraction temperature $\left({ }^{\circ} \mathrm{C}\right.$ ) and ratio of water to material $(\mathrm{mL} / \mathrm{g})$ ) in order to maximize the prebiotic sugar content.

The values of the response prebiotic sugar content (Y) under the different experimental combinations are shown in Table 3. The prebiotic sugar content varied considerably depending on the extraction conditions. The actual prebiotic sugar content ranged from 142.7 to $330 \mathrm{mg} / \mathrm{g}$, whereas the predicted value ranged from 159.8 to $314.2 \mathrm{mg} / \mathrm{g}$.

Among the 17 experiments (actual values), experiment 17 (severity factor of 3.94, extraction temperature of $90{ }^{\circ} \mathrm{C}$, and ratio water to raw material of 30) yielded the highest prebiotic sugar content $(330.0 \mathrm{mg} / \mathrm{g}$ dry steam-exploded wood), whereas experiment 9 (severity factor of 3.64, extraction temperature of $90{ }^{\circ} \mathrm{C}$, and ratio water to raw material of 30 ) afforded the lowest 
A Two-stage Process for Increasing the Yield of Prebiotic-rich Extract from Pinus densiflora

Table 3. Experiments performed using the Box-Behnken design

\begin{tabular}{|c|c|c|c|c|c|}
\hline \multirow{3}{*}{ Run } & \multicolumn{3}{|c|}{ Independent variables } & \multirow{2}{*}{\multicolumn{2}{|c|}{$\begin{array}{c}\text { Dependent variables } \\
Y \text {, Prebiotic sugar } \\
(\mathrm{mg} / \mathrm{g} \text { dry steam-exploded wood }\end{array}$}} \\
\hline & \multirow{2}{*}{$\begin{array}{c}X_{1} \text {, Severity factor } \\
(R 0)\end{array}$} & \multirow{2}{*}{$\begin{array}{c}X_{2} \text {, Extraction } \\
\text { temperature }\left({ }^{\circ} \mathrm{C}\right)\end{array}$} & \multirow{2}{*}{$\begin{array}{l}X_{3} \text {, Ratio of water } \\
\text { to material }(\mathrm{mL} / \mathrm{g})\end{array}$} & & \\
\hline & & & & Actual & Predicted \\
\hline 1 & 4.12 & 90 & 30 & 241.40 & 247.55 \\
\hline 2 & 3.94 & 90 & 40 & 198.20 & 193.01 \\
\hline 3 & 4.12 & 90 & $1 / 50$ & 291.60 & 314.22 \\
\hline 4 & 3.64 & 100 & $1 / 40$ & 218.40 & 192.40 \\
\hline 5 & 3.94 & 90 & 40 & 291.20 & 288.89 \\
\hline 6 & 3.94 & 80 & 30 & 325.30 & 314.22 \\
\hline 7 & 3.64 & 90 & 30 & 298.90 & 314.22 \\
\hline 8 & 4.12 & 80 & 40 & 142.70 & 159.80 \\
\hline 9 & 3.64 & 90 & 50 & 283.70 & 285.05 \\
\hline 10 & 3.94 & 80 & 50 & 232.70 & 252.42 \\
\hline 11 & 4.12 & 100 & 40 & 221.80 & 240.30 \\
\hline 12 & 3.94 & 100 & 50 & 291.20 & 271.48 \\
\hline 13 & 3.94 & 90 & 40 & 197.80 & 213.68 \\
\hline 14 & 3.94 & 90 & 40 & 223.60 & 207.72 \\
\hline 15 & 3.64 & 80 & 40 & 325.30 & 314.22 \\
\hline 16 & 3.94 & 100 & 30 & 231.80 & 222.20 \\
\hline 17 & 3.94 & 90 & 40 & 330.00 & 314.22 \\
\hline
\end{tabular}

prebiotic sugar content $(142.7 \mathrm{mg} / \mathrm{g}$ dry steam-exploded wood).

The response surface shown in Fig. 3A-3C reveals the effect of extraction time and extraction temperature on the prebiotic sugar content.

Three factors at three levels of BBD were used in this study to investigate the influence of operational variables such as severity factor ( $R o=3.64-4.12$ ), extraction temperature $\left(80^{\circ} \mathrm{C}-100{ }^{\circ} \mathrm{C}\right)$, and the ratio of water to material $(30-50)$ on the prebiotic sugar content from $P$. densiflora. From the model developed, a three-dimensional response surface and contour plots were constructed to illustrate the main and interactive effects of the independent variables on the response variable. These graphs, which are easy to understand and draw, were obtained by maintaining one factor constant (in turn at its central level), while varying the other two factors to understand the main and interactive effects of the constant factor on the dependent variables. They can also be used to determine the optimum conditions. As shown in Fig. 3B, the prebiotic sugar content increased with increasing the severity factor up to 3.86 , resulting in a maximum prebiotic sugar content. However, further increase in the severity factor resulted in a decrease in the prebiotic sugar content.

An analysis of variance (ANOVA) was performed to evaluate the predictive model and the variables. The analysis of variance was used to determine the coefficient of determination, and the significance of the linear, quadratic, and interaction effects of the independent variables on the response. 

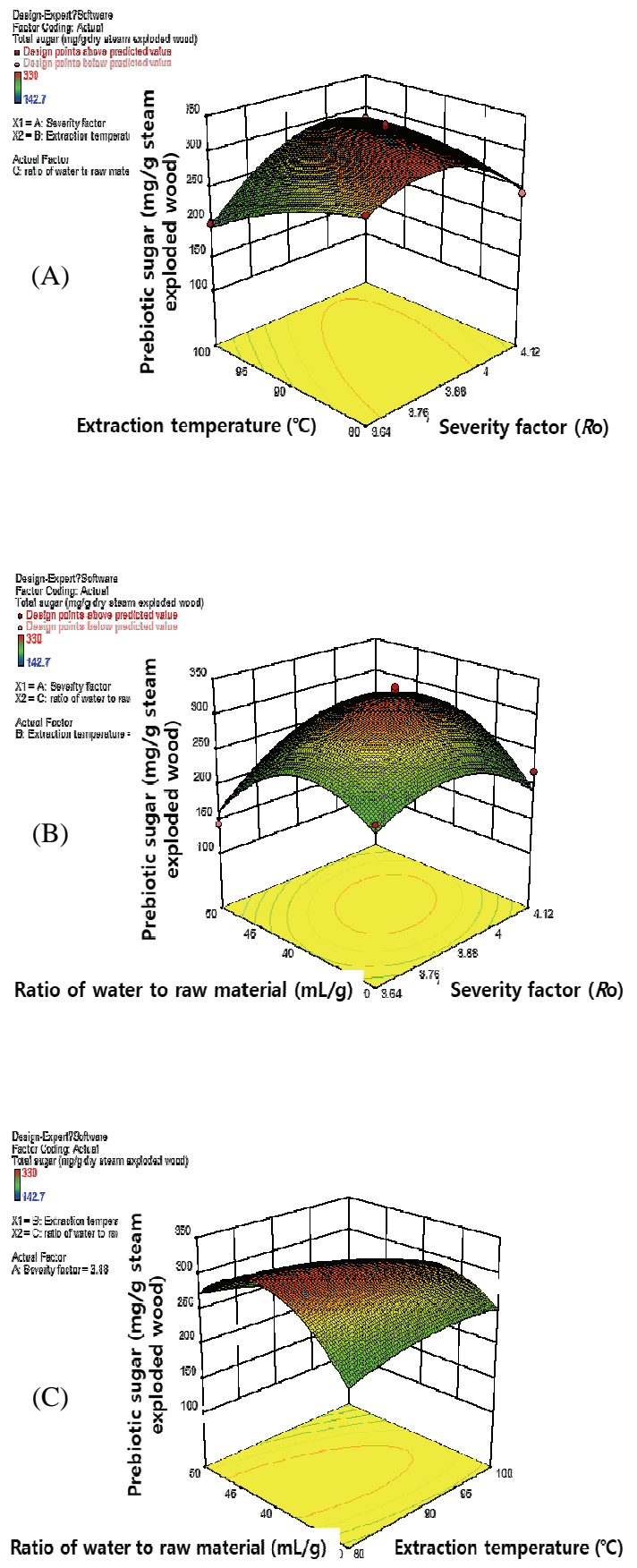
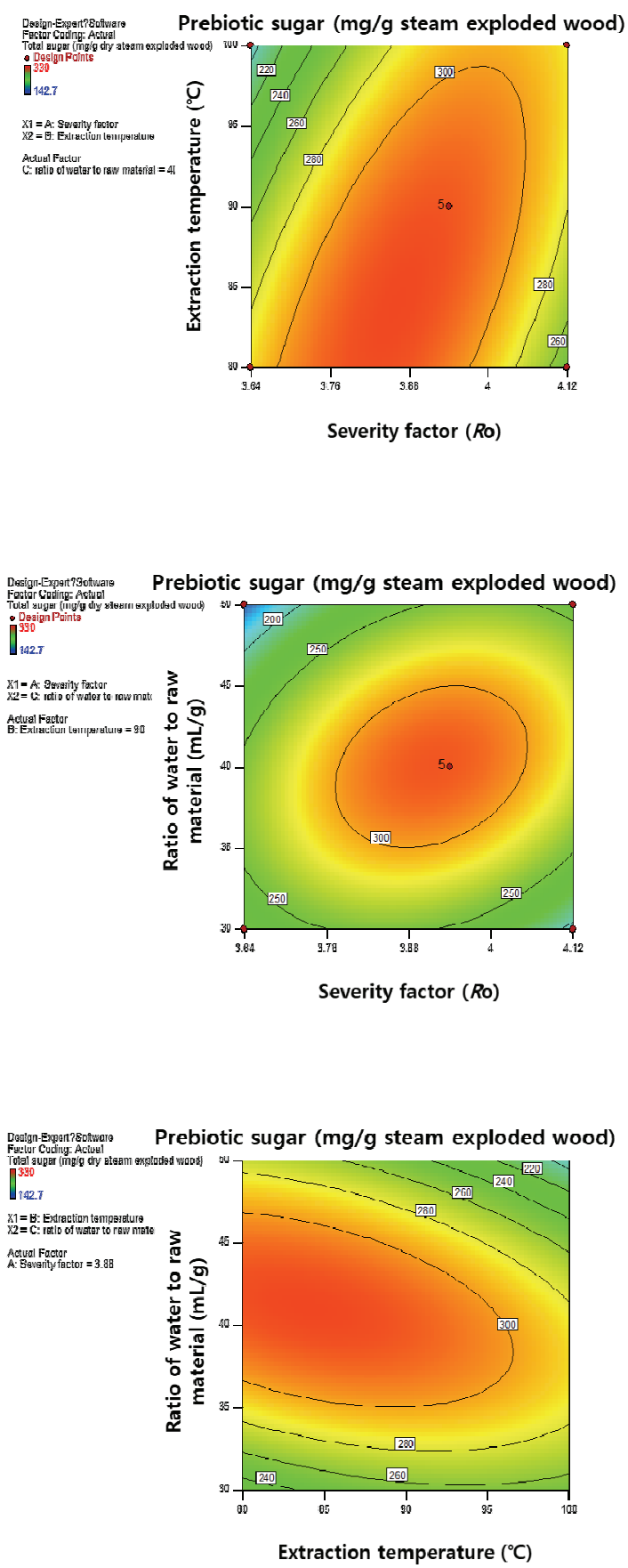

Fig. 3. Response surface plots and contour plots showing the effects of the severity factor and the extraction temperature (A), the severity factor and the ratio of water to material (B), and the ratio of water to material and the extraction temperature $(\mathrm{C})$ on the prebiotic sugar. 
Table 4. ANOVA for the response surface quadratic model

\begin{tabular}{|c|c|c|}
\hline \multirow{2}{*}{$\begin{array}{c}\text { Model } \\
\text { parameter }\end{array}$} & \multicolumn{2}{|c|}{ Prebiotic sugar } \\
\hline & $\begin{array}{l}\text { Regression } \\
\text { coefficient }\end{array}$ & $p$ value \\
\hline Model & & 0.0057 \\
\hline Intercept & -2086.2775 & 0.1242 \\
\hline \multicolumn{3}{|l|}{ Linear } \\
\hline$X_{1}$ & -39.552000 & 0.0203 \\
\hline$X_{2}$ & 27.593000 & 0.0908 \\
\hline$X_{3}$ & 69.558000 & 0.0106 \\
\hline \multicolumn{3}{|l|}{ Quadratic } \\
\hline$X_{1}^{2}$ & -1.864900 & 0.0090 \\
\hline$X_{2}^{2}$ & 0.676500 & 0.0393 \\
\hline$X_{3}^{2}$ & -0.139725 & 0.3192 \\
\hline \multicolumn{3}{|l|}{ Interaction } \\
\hline$X_{1} X_{2}$ & 0.462500 & 0.1274 \\
\hline$X_{1} X_{3}$ & -0.256250 & 0.0968 \\
\hline$X_{2} X_{3}$ & -0.639225 & 0.0017 \\
\hline Lack of fit & & 0.1607 \\
\hline$R^{2}$ & & 0.9130 \\
\hline Adjusted $R^{2}$ & & 0.8012 \\
\hline
\end{tabular}

The significance of regression coefficient was determined using the $p$ value in Table 4 . The corresponding variables become more effective as the $p$ value becomes smaller. Moreover, the $p$ value can be used to evaluate the interaction strength between the independent factors (Muralidhar et al., 2001).As shown for the prebiotic sugar content $(Y)$, it can be seen that the value of the linear coefficient $\left(X_{1}, X_{3}\right)$, the quadratic term coefficient $\left(X_{1}^{2}\right.$ and $\left.X_{2}^{2}\right)$, and the cross-product coefficient $\left(X_{2} \times X_{3}\right)$ were significant, with very small $p$ values $(p<0.05)$. On the other hand, the values of other coefficients $\left(X_{2}, X_{3}^{2}, X_{1} \times X_{2}\right.$, and $\left.X_{1} \times X_{3}\right)$ were found to be insignificant $(p>0.05)$. We observed that the variable with the greatest effect on the prebiotic sugar content was the linear coefficient of the ratio of water to material $\left(X_{3}\right)$. The $R^{2}$ and adjusted
$R^{2}$ values were 0.9130 and 0.8012 for prebiotic sugar content, respectively, which indicates that the highest variation (80\%) of the prebiotic sugar content could be predicted by the models.

\subsection{Prebiotic activity of the prebiotic-rich extract extracted under optimum condition}

Applying the methodology to the desired function, the optimum values for various parameters were obtained as follows: 3.86 for the severity factor $(R o)$, $89.66{ }^{\circ} \mathrm{C}$ for the extraction temperature, and 39.20 for the ratio of water to material $(\mathrm{mL} / \mathrm{g})$.

Under these optimum conditions, the prebiotic sugar content was determined to be $332.45 \mathrm{mg} / \mathrm{g}$. In addition, the prebiotic activity (Bifidobacterium animalis subsp. animalis, Bifidobacterium breve, Bifidobacterium longum, Bifidobacterium bifidum, Lactobacillus casei, Lactobacillus acidophilus, Lactobacillus delbrueckii subsp. bulgaricus, Enterococcus faecium, Enterococcus faecalis, Bacillus subtilis, Bacillus coagulans, Lactococcus gasseri, and Streptococcus salivarius subsp. thermophilus) was evaluated using the $P$. densiflora extract prepared under optimal conditions (Fig. 4). The prebiotic activities were found to be more than 50\% (excluding Bifidobacterium animalis subsp. animalis, Lactobacillus delbrueckii subsp. bulgaricus, and Bacillus coagulans). It is worth noting that the activities of Enterococcus faecium and Enterococcus faecalis were higher than $90 \%$. These data suggest that the extract obtained from $P$. densiflora using the two-stage process can be considered to be a prebiotic sugar-rich extract. Recently, it has been shown that the addition of probiotics containing Enterococcus faecium to broiler diets increased the length of the jejunal and ileal villi. Moreover, increased intestinal villi heights were reported after the addition of Bacillus subtilis in combination with prebiotics. 


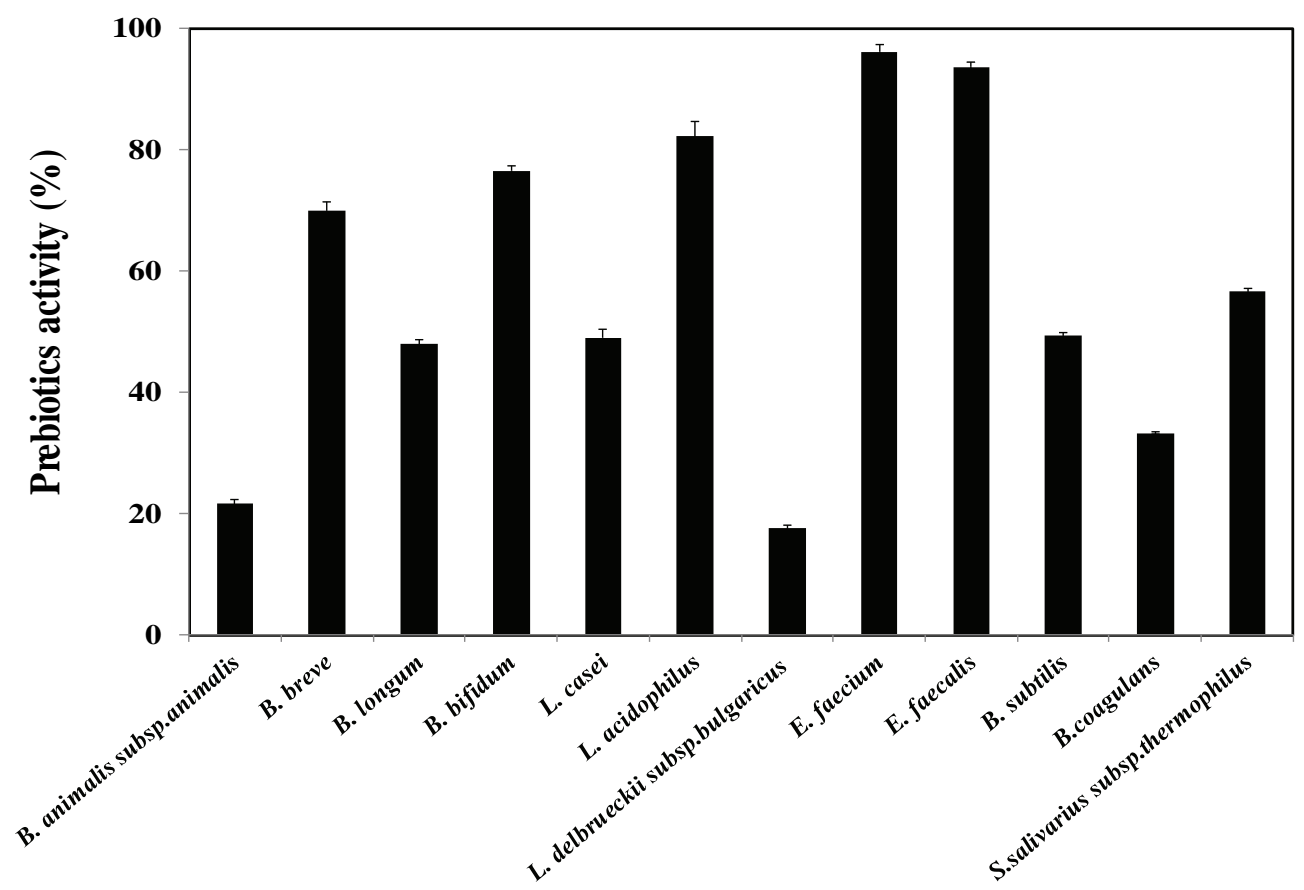

Probiotics

Fig. 4. Prebiotic activity in the presence of the prebiotic-rich extract obtained under optimal conditions.

\section{CONCLUSION}

In this study, a two-stage process including steam explosion and water extraction was performed to efficiently release prebiotic sugars from $P$. densiflora. The simultaneous optimization of the process parameters was carried out by using BBD and RSM, resulting in an optimal severity factor (Ro) of 3.64 4.12, a water extraction temperature between $80^{\circ} \mathrm{C}$ and $90{ }^{\circ} \mathrm{C}$, and a ratio of water to material of $30^{-}$ $50(\mathrm{~mL} / \mathrm{g})$. The data showed that both severity factor $(R o)$ and the ratio of water to material $(w / v)$ had a significant effect on the prebiotic sugar content. Under the optimal conditions of $R o=3.86$, a water extraction temperature of $89.66{ }^{\circ} \mathrm{C}$, and a ratio of water to material of $39.20(\mathrm{w} / \mathrm{v})$, the prebiotic sugar content was 332.45 $\mathrm{mg} / \mathrm{g}$. Enterococcus spp. strains showed good sensitivity to the $P$. densiflora prebiotic-rich extract. In conclusion, this $P$. densiflora prebiotic-rich extract could be considered in the future as an alternative source of prebiotics.

\section{ACKNOWLEDGMENT}

This study was carried out with the support of "R\&D Program for Forest Science Technology (Project No. 2013070D10-1819-AA03)” provided by Korea Forest Service (Korea Forestry Promotion Institute).

\section{REFERENCES}

Aida, F.M.N.A., Shuhaimi, M., Yazid, M., Maaruf, A.G. 2009. Mushroom as a potential source of prebiotics: 
a review. Trends in Food Science and Technology 20(11-12): 567-575.

Crittenden, R.G., Playne, M.J. 1996. Production, properties and applications of food-grade oligosaccharides. Trends in Food Science \& Technology 7(11): 353-361.

Dubois, M., Gilles, K.A., Hamilton, J.K., Rebers, P.A., Smith, P. 1956. Colorimetric method for determination of sugars and related substances. Anal. Chem. 28: 350-356.

Fernandez-Bolanos, J., Felizon, B., Heredia, A., Guillen, R., Jimenez, A. 1999. Characterization of the lignin obtained by alkaline delignification and of the cellulose residue from steam-exploded olive stones. Bioresource Technology 68: 121-132.

Guo, F.C., Williams, B. A., Kwakkel, R.P., Li, H.S., Li, X.P., Luo, J.Y., Li, W.K., Verstegen,

M.W.A. 2004. Effects of mushroom and herb polysaccharides, as alternatives for an antibiotic, on the cecal microbial ecosystem in broiler chickens. Poultry Science 83(2): 175-182.

Jung, J.Y., Choi, M.S., Yang, J.K. 2012. Optimization of Two-stage Pretreatment from Soybean Hull for Efficient Glucose Recovery. Journal of the Korean Wood Science and Technology 40(2): 78-90.

Jung, J.Y., Yang, J.K. 2016. Enhancing Enzymatic Digestibility of Miscanthus sinensis using Steam Explosion Coupled with Chemicals. Journal of the Korean Wood Science and Technology 44(2): 218-230.

Jung, J.Y., Ha, S. Y., Yang, J.K. 2017. Response Surface Optimization of Phenolic Compounds Extraction From Steam Exploded Oak Wood (Quercus mongolica). Journal of the Korean Wood Science and Technology 45(6): 809-827.

Kim, H.Y., Hong, C.Y., Kim, S.H., Yeo, H.M., Choi, I.G. 2015. Optimization of The Organosolv Pretreatment of Yellow Poplar for Bioethanol Production by Response Surface Methodology. Journal of the
Korean Wood Science and Technology 43(5): 600612.

Kurd, F., Samavati, V. 2015. Water soluble polysaccharides from Spirulina platensis: Extraction and in vitro anti-cancer activity. International Journal of Biological Macromolecules 74: 498-506.

Lee, J.M., Jameel, H., Venditti, R.A. 2010. A comparison of the autohydrolysis and ammonia fiber explosion (AFEX) pretreatments on the subsequent enzymatic hydrolysis of coastal Bermuda grass. Bioresource Technology 101: 5449-5458.

Linares-Pasten, A., Andersson, J.M., Karlsson, N.E. 2014 Thermostable Glycoside Hydrolases in Biorefinery Technologies. Current Biotechnology 3(1): 26-44.

Macfarlane, S., Macfarlane, G.T., Cummings, J.H. 2006. Review article: prebiotics in the gastrointestinal tract. Alimentary Pharmacology and Therapeutics 24: 701-714.

Martin-Sampedro, R., Revilla, E., Villar, J.C., Eugenio, M.E. 2014. Enhancement of enzymatic saccharification of Eucalyptus globulus: steam explosion versus steam treatment. Bioresour Technol 167: 186-191.

Michida, H., Tamalampudi, S., Pandiella, S.S. Webb, C., Fukuda, H., Kondo, A. 2006. Effect of cereal extracts and cereal fiber on viability of Lactobacillus plantarum under gastrointestinal tract conditions. Biochemical Engineering Journal 28(1): 73-78.

Roberfroid, M.B. 2000. Chicory fructooligosaccharides and the gastrointestinal tract. Nutrition 16(7/8): 677-679.

Rycroft, C.E., Jones M.R., Gibson, G.R., Rastall, R.A. 2001. A comparative in vitro evaluation of the fermentation properties of prebiotic oligosaccharides. Journal of applied microbiology 91(5): 878-887.

Sabater-Molina, M., Larqué, E., Torrella, F., Zamora, S. 2009. Dietary fructooligosaccharides and potential benefits on health. Journal of Physiology and Biochemistry 65(3): 315-328. 
Sendra, E., Fayos, P., Lario, Y., Fernández-López, J., Sayas-Barberá, E., Pérez-Alvarez, J.A. 2008. Incorporation of citrus fibers in fermented milk containing probiotic bacteria. Food Microbiology 25(1): 13-21.

Tumuluru, J.S., Sokhansanj, S., Hess, J.R.,Wright, C.T. \& Boardman, R.D. 2011. A Review on Biomass Torrefaction Process and Product Properties for Energy Applications. Industrial Biotechnology 7: 384-401.

Warrand, J. 2006. Healthy Polysaccharides. Food Technology and Biotechnology 44(3): 355-370.

Zhang, S., Dong, Q., Zhang, L., Xiong, Y. 2006. Effects of water washing and torrefaction on the pyrolysis behavior and kinetics of rice husk through TGA and Py-GC/MS. Bioresource Technology 199: 352-361.

Zhang, Z., Wang, X., Zhao, M., Qian, K. 2014. Optimization of polysaccharides extraction from Clematis huchouensis Tamura and its antioxidant activity. Carbohydrate Polymers 111(13): 762-767.

Zhong, K., Wang, Q. 2010. Optimization of ultrasonic extraction of polysaccharides from dried longan pulp using response surface methodology. Carbohydrate Polymers 80(1): 19-25.

Zhu, C., Zhai, X., Li, L., Wu, X., Li, B. 2015. Response surface optimization of ultrasound-assisted polysaccharides extraction from pomegranate peel. Food Chemistry 177(15): 139-146. 